\title{
Anti-TNFa Biologics in the Pharmacotherapy of Rheumatoid Arthritis: Effectiveness and Safety of Infliximab, Adalimumab and Etanercept
}

\author{
Zainab Bahardeen ${ }^{*}$ \\ ${ }^{1}$ BMS School of Science, Colombo-06, Sri Lanka \\ Corresponding Author: Zainab Bahardeen, BMS School of Science, No. 591, Galle Road, Colombo-06, Sri Lanka. Tel: +94- \\ 702181523, Email: zainabbahardeen@gmail.com
}

Received June 9, 2019; Accepted August 28, 2019; Online Published September 26, 2019

\begin{abstract}
Rheumatoid arthritis (RA) is a chronic inflammatory disease of unknown etiology. Traditionally, pharmacotherapy of RA involved nonsteroidal anti-inflammatory drugs (NSAIDs) and disease-modifying antirheumatic drugs (DMARDs). However, focus now has been diverted to biologic DMARDs. Tumor necrosis factor alpha (TNF $\alpha$ ) plays pleiotropic roles in RA pathogenesis. Hence, anti-TNF biologics offer attractive therapeutic utility. Literature contains numerous studies comparing either the effectiveness or the safety of the three drugs of interest; infliximab, adalimumab and etanercept, in terms of; patient response to treatment in a cohort and in vitro properties of the drugs. Concern at the absence of a review that comprehensively exploits both the effectiveness and safety, this review aims towards not only presenting the observed discrepancies, but also discussing the causes for them and providing experimental results from studies obtained via an extensive literature survey. Critical analysis of the effectiveness and safety profiles of licensed anti-TNF agents; infliximab, adalimumab and etanercept revealed that, a single drug cannot be named as the most efficacious. Nevertheless, anti-TNF therapy associates challenges of systemic toxicity, heterogenous patient response and partial remission. Advancement in research aiming at alleviating the existing drawbacks of anti-TNF therapy is essential.

Keywords: Rheumatoid arthritis, Anti-TNF therapy, Pharmacotherapy

Citation: Bahardeen Z. Anti-TNF $\alpha$ biologics in the pharmacotherapy of rheumatoid arthritis: effectiveness and safety of infliximab, adalimumab and etanercept. Int J Med Rev. 2019;6(3):92-100. doi:10.29252/ijmr-060305.
\end{abstract}

\section{Introduction}

Rheumatoid Arthritis (RA) is a chronic inflammatory autoimmune disease of unknown etiology. It characteristically presents with joint inflammation that leads to joint damage, loss of function and ultimately disability. ${ }^{1-3}$ Moreover, RA affects approximately $1 \%$ of the global adult population, occurring in 20-50 cases per 100000 annually, ${ }^{4,5}$ incidence being two to three times common in women than in men.,

Nevertheless, though RA primarily occurs in the joints, it involves extra articular manifestations and systemic comorbidities. Substantial individual and socioeconomic burden resulting from musculoskeletal defects, reduced quality of life, declined work capacity and increased medical costs remain serious concerns..$^{8-10}$

Furthermore, though recent advances have contributed positively to its course, RA continues to present challenges to modern medicine. The discovery of tumor necrosis factor alpha (TNFa) as the central dogma in the pathogenesis of $\mathrm{RA}^{11,12}$ resulted in broad consensus that anti-TNF biologics will be an effective treatment approach. Subsequently, antiTNF biologic therapy did show significant improvements in the quality of life in majority of RA patients. ${ }^{13,14}$ However, the concerns arose when an estimated $30 \%-40 \%$ of patients remained unresponsive to treatment while very few enjoyed complete remission. ${ }^{15,16}$ Moreover, association of biologics with increased risk of adverse effects suggested the necessity of reviewing the effectiveness and safety of existing therapeutics. ${ }^{17,18}$ Thus, this review exploits the comparison of effectiveness and safety of three prominent anti-TNFa biologics, infliximab, adalimumab and etanercept, aspiring to provide platform and background for the development of more effective and safer therapeutics.

\section{Pharmacotherapy}

According to the treatment guidelines published by the American College of Rheumatology, ${ }^{19}$ goals of RA pharmacotherapy are; reduction of disease activity, establish remission, tight control through medical management and prevention of further joint damage. However, Alam et $\mathrm{al}^{20}$ and Murphy et $\mathrm{al}^{21}$ address improvement of the quality of life as another prominent goal.

Traditionally, RA has been treated with non-steroidal antiinflammatory drugs (NSAIDs), glucocorticoids and diseasemodifying antirheumatic drugs (DMARDs). The NSAIDs and glucocorticoids remain first line drugs, whereas DMARDs are second line drugs. ${ }^{22,23}$

Copyright $\odot 2019$ The Author(s). This is an open-access article distributed under the terms of the Creative Commons Attribution License (http:// creativecommons.org/licenses/by/4.0), which permits unrestricted use, distribution, and reproduction in any medium, provided the original work is properly cited. 
DMARDs are defined as medications that reduce or halt the disease progression by rapid and sustained suppression of inflammation, but incapable of curing the disease. ${ }^{24}$ They can be categorized as, conventional DMARDs (cDMARDs) and newly introduced biologic DMARDs (biologics). Among cDMARDs, the most efficacious is methotrexate (MTX), ${ }^{25}$ due to its highest retention rates. Nevertheless, combination of MTX with one or more of the other cDMARDs or combination of MTX with a biologic has shown improved response in clinical trials than monotherapies of DMARDs. ${ }^{26,27}$

\section{Biologics}

Biologics are drugs produced from living organisms or contain components of living organisms (blood, blood components, cells, allergens, genes, tissues and recombinant proteins), ${ }^{28}$ that have been formulated to specifically block or alter the function of cytokines.

\section{Anti-TNF $\alpha$ Biologics}

Placing TNFa at the center of RA pathogenesis has led RA to be the first disease for which anti-TNF biologics were used. $^{28}$ In clinical settings, anti-TNF biologics have been efficacious in $60 \%-70 \%$ of RA patients whose disease activity was persistent despite cDMARD treatment. ${ }^{29}$ Apart from improving the clinical symptoms of RA, TNF antagonists provide protection against joint destruction, disability and improve quality of life, ${ }^{30}$ thus addressing most of the aims of RA pharmacotherapy.



Figure 1. Schematic Illustration of Molecular Structures of Anti-TNF $\alpha$ Biologics (from left to right; infliximab, adalimumab and etanercept). ${ }^{32}$
Currently, three anti-TNF biologics; infliximab, adalimumab and etanercept approved by the Food and Drug Administration (FDA) are utilized in clinical settings. ${ }^{31}$

Considering the structures of these drugs (Figure 1), infliximab is a chimeric monoclonal antibody that has been genetically engineered by the fusion of two murine TNFbinding epitopes and a Fc portion of a human IgG1. Conversely, adalimumab is a human monoclonal antibody engineered by the combination of two human TNF-binding epitopes and a Fc portion of a human IgG1. Moreover, etanercept is the combination of two naturally occurring soluble human TNF receptors and a Fc portion of a human IgG1.

Furthermore, anti-TNF biologics currently in phase III trials; golimumab, a human monoclonal antibody; ${ }^{33}$ and certolizumab pegol, a pegylated fab' fragment of a humanized monoclonal antibody against $\mathrm{TNF}^{34}$ are expected to yield similar results as the licensed agents.

\section{Comparison of Effectiveness}

Comparison of Clinical Properties

Clinical efficacy of infliximab, adalimumab and etanercept in RA is achieved by their inhibitory properties on; cell activation, cell proliferation, cytokine and chemokine production, inflammation, immune regulation, angiogenesis, and extracellular matrix degradation. ${ }^{30}$ Thus, comparison of the clinical properties (Table 1) of anti-TNF biologics is essential to review their effectiveness.

According to Kaymakcalan et al, ${ }^{35}$ measurements on binding affinities, using BIAcore and radioimmunoassay methods, reported higher values for sTNFa than mTNFa. on the contrary, Sakorafas et $\mathrm{al}^{36}$ reported equal affinities for both sTNFa and mTNFa, when kinetic exclusion assay was employed for the measurements, suggesting that the discrepancy in findings may be a consequence of utility of different assays. Moreover, Kaymakcalan et $\mathrm{al}^{35}$ suggested that, this inconsistency may be due to structural variations (Figure 2). However, it is yet unknown whether the binding affinities of these drugs play an important role in different clinical outcomes. ${ }^{49}$

Considering CDC, both infliximab and adalimumab show higher effectiveness, whereas etanercept remain less effective. $\mathrm{CDC}$ involves binding of $\mathrm{C} 1 \mathrm{q}$ to $\mathrm{CH} 2$ domain of IgG1, which

Table 1. Comparison of Clinical Properties of Infliximab, Adalimumab and Etanercept

\begin{tabular}{|c|c|c|c|c|c|}
\hline \multicolumn{2}{|c|}{ Property } & \multirow{2}{*}{$\frac{\text { Infliximab }}{+++}$} & \multirow{2}{*}{$\frac{\text { Adalimumab }}{+++}$} & \multirow{2}{*}{$\frac{\text { Etanercept }}{+++}$} & \multirow{2}{*}{$\frac{\text { Reference(s) }}{35}$} \\
\hline \multirow{3}{*}{ Binding } & sTNF $\alpha$ & & & & \\
\hline & \multirow{2}{*}{ mTNF $\alpha$} & ++ & ++ & ++ & 35 \\
\hline & & +++ & +++ & +++ & 36 \\
\hline \multirow{4}{*}{$\begin{array}{l}\text { Functional properties shown on } \\
\text { mTNF } \alpha \text { expressing cells }\end{array}$} & CDC & +++ & +++ & + & $37,38,39$ \\
\hline & \multirow{2}{*}{ ADCC } & +++ & +++ & +++ & 38 \\
\hline & & +++ & +++ & + & 37,39 \\
\hline & Reverse- signaling & +++ & +++ & - & 38 \\
\hline \multicolumn{2}{|c|}{ Downregulation of pro-inflammatory cytokines (IL-1, IL-6, IL-8, IL-18, GM-CSF) } & +++ & +++ & +++ & $40,41,42$ \\
\hline \multicolumn{2}{|c|}{ Upregulation of anti-inflammatory cytokines (IL-4, IL-10, IL-12) } & +++ & +++ & - & $43,44,45$ \\
\hline \multicolumn{2}{|l|}{ Improving $\mathrm{T}_{\text {reg }}$ and Suppressing $\mathrm{T}_{\text {eff }}$} & +++ & +++ & - & 46 \\
\hline \multicolumn{2}{|l|}{ Induction of apoptosis } & +++ & +++ & - & $38,44,47,48$ \\
\hline
\end{tabular}




\section{A INTRINSIC AFFINITY MEASUREMENT ON SOLID PHASE}

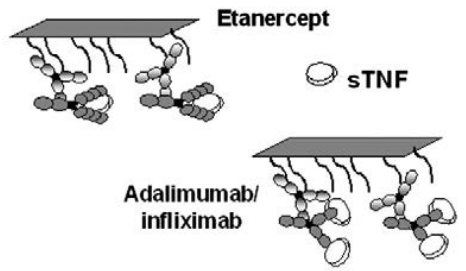

\section{B AVIDITY MEASUREMENT IN SOLUTION} PHASE


C BINDING TO mTNF ON CELLS
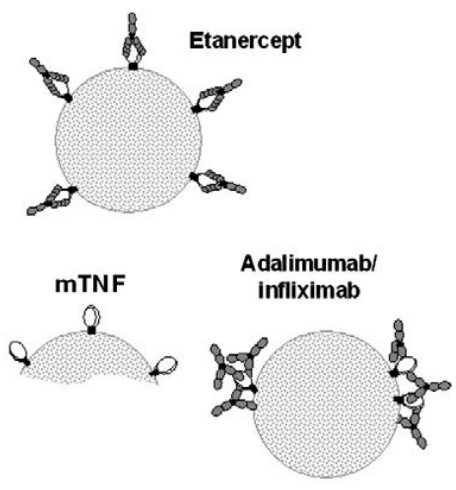

Figure 2. Illustration of Binding Interactions Between Anti-TNF $\alpha$ Agents (Black) and TNF $\alpha$, as Captured by Biosensor Chips Covalently Attached to Polyclonal Goat Anti-human IgG Fc. Reprinted with permission from Kaymakcalan et al. ${ }^{35}$

initiates the classical complement cascade, thus leading to the eventual formation of membrane attack complex and the resultant cell lysis. ${ }^{39}$ Therefore, this discrepancy is believed to be a result of the structure-influenced binding abilities of TNF antagonists to the first complement component, C1q. Accordingly, Arora et $\mathrm{al}^{37}$ evaluated binding abilities of the three drugs to $\mathrm{C} 1 \mathrm{q}$, using radiolabeled ${ }^{125} \mathrm{I}$ bound to immobilized $\mathrm{Clq}$ (Figure 3). Both infliximab and adalimumab showed significant increase in binding along with the increment of C1q concentration, whereas etanercept reported only a slight increase.

Moreover, infliximab, adalimumab and etanercept commonly possess the Fc portion of IgG1 (Figure 4), whose $\mathrm{CH} 2$ domain activates C1q. However, etanercept does not carry the $\mathrm{CH} 1$ domain and hinge region of $\operatorname{IgG} 1 .^{50}$ This results in conformational hindrance for the proper binding with $\mathrm{C} 1 \mathrm{q}$, thus making its potency low. Nevertheless, $\mathrm{CH} 1$ domain being the platform for activation of complement component $\mathrm{C} 3,{ }^{51}$ and hinge region being necessary for the formation of membrane attack complex ${ }^{52}$ further explain the reduced CDC activity by etanercept.

As for ADCC, all three drugs showed similar activity, when mTNF-transfected Jurkat T cells were used as target, ${ }^{38}$ whereas infliximab and adalimumab were efficacious than etanercept in NSO cells ${ }^{39}$ and CHO cells. ${ }^{37}$ Therefore, this discrepancy in etanercept-induced ADCC may be perceived as a consequence of the difference in the species of target cell used. However, structurally all three drugs possess both $\mathrm{CH} 2$ and $\mathrm{CH} 3$ domains of the $\mathrm{Fc}$ region of IgG1 (Figure 4), which are crucial for the anti-TNF agents to bind with $\mathrm{Fc}$ receptors of NK cells. ${ }^{53}$ The NK cells in turn lyse of the target cells by granzyme B and perforin. Consequently, all three drugs should show equal ADCC activity, theoretically.

Reverse signaling, a function of TNF agonists for the inhibition of TNFa-producing cells, is mediated by pathways independent of CDC and ADCC (Figure 5). However, upon binding to mTNFa-expressing Jurkat T cells, both infliximab and adalimumab, induce apoptosis and cell cycle G0/G1 arrest, whereas etanercept did not. Watts et $\mathrm{al}^{55}$ reveal that, this inability of etanercept may be due to the absence of complementary residues to bind with serine residues of $\mathrm{mTNF} \alpha$ in order to initiate apoptotic signaling.

As for downregulation of pro-inflammatory cytokines, all three agents have been equally efficacious. According to



Figure 3. Binding abilities of anti-TNF agents (A) etanercept, (B) adalimumab and (C) infliximab to C1q, evaluated by radiolabeled ${ }^{125}$ I bound to immobilized C1q. Reprinted with permission from Arora et al. ${ }^{37}$ 


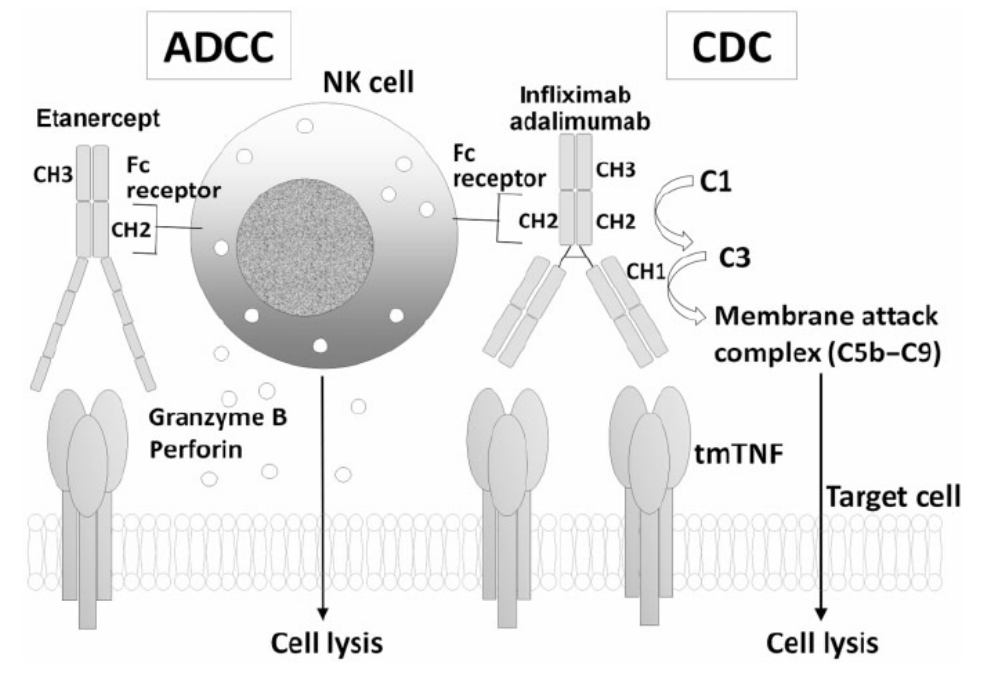

Figure 4. Structures of Infliximab, Adalimumab and Etanercept With Domains Relevant to CDC and ADCC Activity. ${ }^{54}$

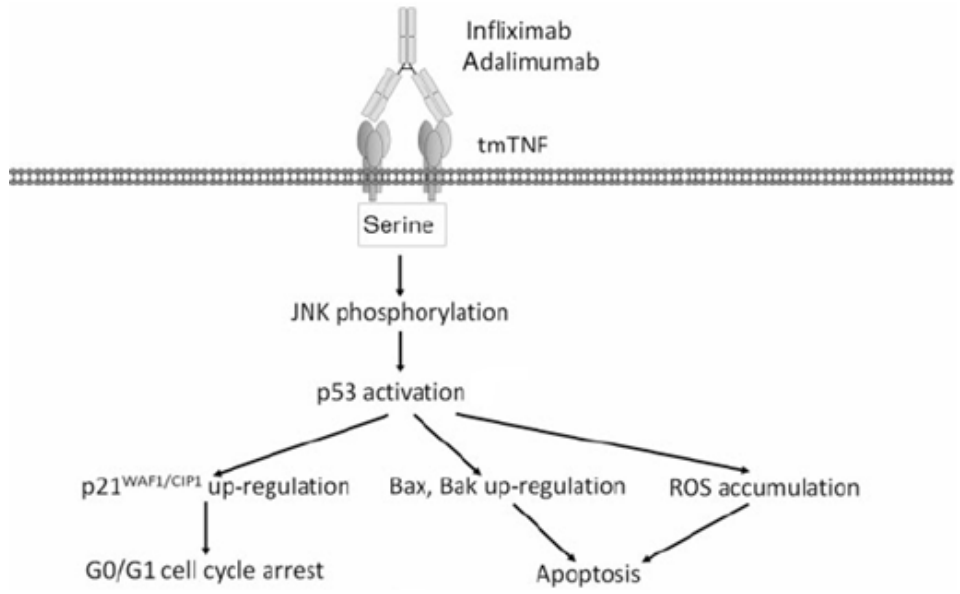

Figure 5. Mechanism of Reverse Signaling by Infliximab and Adalimumab. ${ }^{54}$

Ohshima et al, ${ }^{45}$ elevated serum IL-6 levels rapidly diminished in each set of patients who received one of the three agents. Nevertheless, etanercept downregulated IFN- $\gamma$, GM-CSF and IL- $18^{42}$ production in vitro as efficiently as infliximab and adalimumab.

However, infliximab and adalimumab have successfully augmented anti-inflammatory cytokine levels in vitro, whereas etanercept has failed to do so. According to Mitoma et a ${ }^{43}$ and Horiuchi et al, ${ }^{54}$ all three agents stimulated mTNFa-expressing Jurkat $\mathrm{T}$ cells, whereas only infliximab and adalimumab upregulated IL-10 levels in vitro. Nevertheless, elevated serum IL-10 levels in RA patients were further augmented in patients treated with infliximab and adalimumab, whereas no change was observed in patients who were given etanercept. ${ }^{45}$

Considering induction of apoptosis, both the monoclonal antibody drugs have been efficacious, whereas the receptor protein has been ineffective. Infliximab and adalimumab have induced apoptosis in cells which express mTNFa such as; lamina propria T-lymphocytes, ${ }^{48}$ monocytes, ${ }^{44}$ and macrophages. ${ }^{40}$ Conversely, they have failed to induce apoptosis in cells which do not express mTNFa, such as lymphocytes. ${ }^{47}$ Therefore, induction of apoptosis by infliximab and adalimumab, can be understood as a process dependent on reverse-signaling; a functional property shown only on mTNFa-expressing cells. Thus, the inability of etanercept to induce apoptosis can be understood as a consequence of its ineffectiveness in reverse signaling.

Moreover, improvement of $\mathrm{T}_{\text {reg }}$ and suppression of $\mathrm{T}_{\text {eff }}$ by infliximab and adalimumab, is believed to be the result of their influence on the viability $\mathrm{T}_{\text {reg }}$ and $\mathrm{T}_{\text {eff }}{ }^{56}$ through mechanisms such as induction of apoptosis. Consequently, etanercept fails to regulate the activity of $\mathrm{T}$ cells ${ }^{55}$ as it is inefficacious in inducing apoptosis.

Comparison of Patient Response to Treatment

Effectiveness can be further assessed by reviewing the patient response to treatment (Table 2). Regardless when given as monotherapy or in combination with MTX, etanercept has shown augmented response in clinical trials. Nevertheless, it has reported high retention rates as both first- and second-line biologics. Furthermore, literature considers etanercept as the drug of choice for short term therapy. Therefore, collectively, etanercept shows highest rates in overall patient response to therapy. Furthermore, adalimumab can be considered the 
Table 2. Comparison of Patient Response to Treatment in Infliximab, Adalimumab and Etanercept Therapy

\begin{tabular}{|c|c|c|c|c|}
\hline Criterion & Infliximab & Adalimumab & Etanercept & Reference(s \\
\hline $\begin{array}{l}\text { Drug monotherapy vs. } \\
\text { MTX monotherapy }\end{array}$ & ++ & + & +++ & $57-59$ \\
\hline $\begin{array}{l}\text { Drug + MTX } \\
\text { combination therapy }\end{array}$ & + & ++ & +++ & $60-65$ \\
\hline $\begin{array}{l}\text { Short term therapy }(<1 \\
\text { year })\end{array}$ & + & +++ & +++ & 66 \\
\hline $\begin{array}{l}\text { Long term therapy (>1 } \\
\text { year) }\end{array}$ & + & +++ & ++ & 66 \\
\hline Disease remission & + & +++ & ++ & 67 \\
\hline $\begin{array}{l}\text { Retention rate as } 1^{\text {st }} \\
\text { line biologic }\end{array}$ & ++ & ++ & +++ & 68 \\
\hline $\begin{array}{l}\text { Retention rate as } 2^{\text {nd }} \\
\text { line biologic }\end{array}$ & ++ & ++ & +++ & 68 \\
\hline
\end{tabular}

second most efficacious drug in patients due to highest rate of disease remission and being the drug of choice in long term therapy. Nevertheless, infliximab appears to be the least efficacious in terms of treatment response.

\section{Contraindications}

As any other therapeutic method, anti-TNFa biologic therapy too has its contraindications (Table 3 ), which pose a challenge to its therapeutic role.

Table 3. Side Effects Associated With Anti-TNF $\alpha$ Biologic Therapy

\begin{tabular}{lcc}
\hline Serious Adverse Events & Infections & Infusion Reactions \\
\hline $\begin{array}{l}\text { MI and congestive heart } \\
\text { failure }\end{array}$ & Reactivation of TB & Pruritus \\
Lymphoma & Histoplasmosis & Rash \\
NMSC & Listeriosis & Dyspnea \\
Demyelination & Candidiasis & Hypertension \\
Hematological effects & Aspergillosis & Chest discomfort \\
LFT abnormalities & Pneumocystis & Nausea \\
\hline
\end{tabular}

Abbreviations: TB, tuberculosis; MI, myocardial infarction; NMSC, nonmelanoma skin cancer; LFT, liver function tests.

Adapted from Dogra and Khullar. ${ }^{69}$
Initially, anti-TNFa biologics were found to reduce the risk of cardiac diseases. ${ }^{70}$ However, along with the reported increment of total cholesterol and low-density lipoprotein levels subsequent to anti-TNFa therapy, ${ }^{71}$ they are considered to impose risk for $\mathrm{MI}$ and congestive heart failure.

Reportedly, TNFa regulates the cytokine mediated cancer immunosurveillance, and Ramanarayanan et $\mathrm{al}^{72}$ suggest that, blockage of TNFa may revoke anti-tumor immunity and increase the risk of malignancies. Based on more extensive data, current FDA guidelines report an augmented risk of lymphoma in TNF antagonist treated subjects. ${ }^{73}$

Moreover, TNF antagonists reportedly destroy macrophagic granulomas containing Mycobacterium tuberculosis ${ }^{74}$ via the induction of apoptosis. Therefore, treatment with anti-TNF agents associate high risk of reactivation of TB. Nevertheless, similar mechanisms have been related to the occurrence of other opportunistic infections. ${ }^{75}$

In the case of monoclonal antibody drugs, formation of antiinfliximab and anti-adalimumab antibodies ${ }^{76}$ cause secondary inefficacy and may cause complete unresponsiveness eventually. Nevertheless, the presence of such antibodies may explain the increased infusion reactions reported with infliximab and adalimumab therapy. ${ }^{77,78}$

\section{Comparison of safety}

Numerous study groups have attempted to evaluate and compare the safety of infliximab, adalimumab and etanercept (Table 4). According to majority of literature, infliximab is the least safe as it is associated with the highest percentage of serious adverse events and infections. However, infliximab reports the least percentage of infusion reactions. Moreover, due to no serious adverse effects being reported at all, literature considers it the safest among the three. Etanercept reports a considerable percentage of infections. However, studies suggest that the increased infusion reactions caused by etanercept do not affect it being the safest, as infusion reactions can be easily dealt by applying cool pack $\left(4^{\circ} \mathrm{C}\right)$, application of topical corticosteroids or by rotating the injection site. ${ }^{79}$ As for adalimumab, it reports intermediate safety profile as it is associated with a considerable percentage

Table 4. Comparison of Safety of Infliximab, Adalimumab and Etanercept

\begin{tabular}{|c|c|c|c|c|c|c|c|}
\hline \multirow[b]{2}{*}{ Drug } & \multirow[b]{2}{*}{ Study Group/Year } & \multirow[b]{2}{*}{ Reference } & \multicolumn{2}{|l|}{ Study Population } & \multicolumn{3}{|c|}{ Adverse Effects (\%) } \\
\hline & & & Country & Number & $\begin{array}{l}\text { Serious Adverse } \\
\text { Events }\end{array}$ & Infections & $\begin{array}{l}\text { Infusion } \\
\text { Reactions }\end{array}$ \\
\hline Infliximab & Lipsky et al, 2000 & 80 & UK & 67 & 85.1 & 87.5 & - \\
\hline Infliximab & St.Clair et al, 2004 & 65 & USA & 749 & 13.7 & 27.2 & 0.5 \\
\hline Infliximab & Westhovens et al, 2006 (START study) & 81 & USA & 512 & 10.7 & 16.4 & - \\
\hline Etanercept & Weinblatt et al, 1999 & 82 & UK & 89 & - & 57.3 & 47.2 \\
\hline Etanercept & Bathon et al, 2000 & 83 & UK & 415 & - & 12.0 & 33.7 \\
\hline Etanercept & Van der Heijde et al, 2006 (TEMPO study) & 63 & USA & 223 & - & 6.2 & 20.6 \\
\hline Adalimumab & Weinblatt et al, 2003 (ARMADA trial) & 84 & USA & 140 & - & 6.4 & 24.2 \\
\hline Adalimumab & Van de Putte et al, 2004 & 85 & Europe, Canada and Australia & 434 & - & 18.6 & 10.6 \\
\hline Adalimumab & Keystone et al, 2004 & 86 & USA and Canada & 419 & 4.7 & 11.4 & 24.1 \\
\hline Adalimumab & Breedveld et al, 2005 (PREMIER study) & 87 & Australia, Europe and North America & 799 & 39.6 & 3.6 & - \\
\hline
\end{tabular}


of adverse effects, but less than that of infliximab and greater than that of etanercept.

Moreover, Table 5 further suggests etanercept as the safest and infliximab, the least safe among the three anti TNF agents.

\section{Future Insight}

Despite the clinical efficacy of anti-TNF agents, prevalence of potential drawbacks has led research to focus on finding solutions to alleviate negativities. A major drawback is failure to produce response in some patients or producing only a partial response. Nevertheless, molecular remission and the capacity to re-establish immunological tolerance remain elusive till date. Apart from that, systemic toxicity and complications of anti-TNF therapy remain a major challenge. Moreover, there is a notable absence of reliable predictive biomarkers to monitor therapeutic response and toxicity.

Ferrari et $\mathrm{al}^{91}$ suggest the recruitment of novel strategies; 'Trojan Horse' and 'Guided Missile' drug delivery systems, to actively target and deliver anti-TNFa agents to target sites. Trojan horse drug delivery combines the two theories of polymer conjugation and nanoparticulate drug delivery (Figure 6), whereas guided missile drug delivery addresses formulating drugs as antibody conjugates and bispecific antibodies (Figure 7). Therefore, formulation of anti-TNF

Table 5. Comparison of Safety of Infliximab, Adalimumab and Etanercept

\begin{tabular}{|c|c|c|c|c|}
\hline Criterion & Infliximab & Adalimumab & Etanercept & Reference(s) \\
\hline Drug survival rate & ++ & + & +++ & 57 \\
\hline Risk of infection & +++ & ++ & + & 88,89 \\
\hline $\begin{array}{l}\text { Discontinuation } \\
\text { due to adverse } \\
\text { effects }\end{array}$ & +++ & ++ & + & $\begin{array}{c}63,81,83 \\
85,87,90\end{array}$ \\
\hline
\end{tabular}

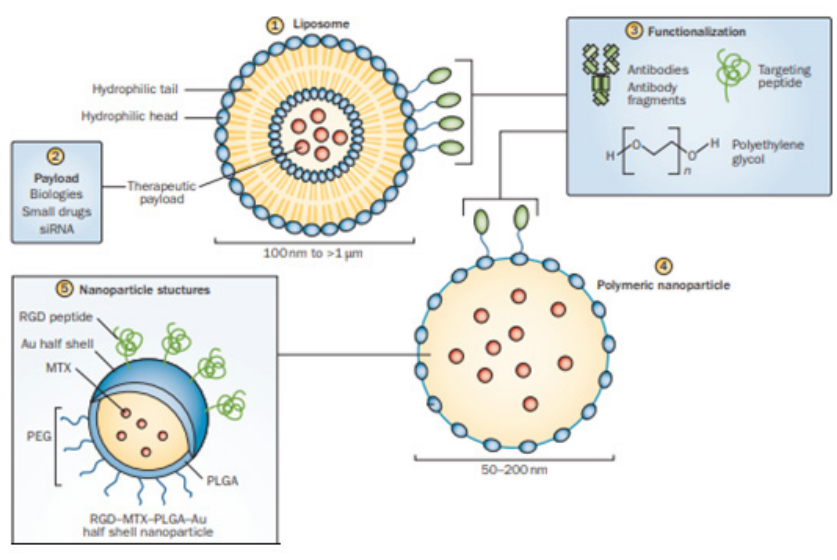

Figure 6. 'TROJAN HORSE' APPROACHES for Drug Delivery. Liposomes can be engineered to bind drugs and degrade only upon reaching the target site, thus it is believed to limit systemic toxicity. Moreover, nanoparticles can be conjugated to polymers that contain encapsulated drugs, thus promote target-specific delivery. Trojan horse drug delivery suggests formulation of drugs as polymeric nanoparticles by combining the above two theories, to achieve combined efficacy. An example is [5] conjugation of RGD to a methotrexate-loaded PLGA-Au nanoparticle32 providing active targeting of $\alpha \mathrm{V} \beta 3$-expressing endothelial cells. Abbreviations: PLGA, poly(lactic-co-glycolic) acid; RGD, Arg-Gly-Asp peptide; siRNA, small interfering RNA. ${ }^{91}$ biologics according to these drug delivery concepts is believed to confer improved pharmacokinetic properties, promote in situ action and decrease systemic toxicity.

Nevertheless, researchers believe that gene array analysis will help define individual response to treatment, thus alleviate the heterogenicity in patient response..$^{93}$

\section{Conclusion}

In conclusion of the review, it is evident that in terms of effectiveness related to clinical properties, both the monoclonal antibody drugs are efficacious than the receptor protein. However, considering patient response to treatment, both adalimumab and etanercept were superior to infliximab. Considering safety, etanercept is the safest whereas infliximab, is the least safe. Thus, a single drug cannot be named as the most efficacious in terms of both effectiveness and safety. Furthermore, systemic toxicity of anti-TNF agents, induction of heterogenous responses in patients, and above all, inability to achieve disease remission remain as challenges of current anti-TNF therapy.

Therefore, the improvement in structures and pharmacokinetic properties of anti-TNF agents may alleviate the reported drawbacks. Furthermore, it may lead to successful treatment of symptoms, improve safety profiles, and reduce
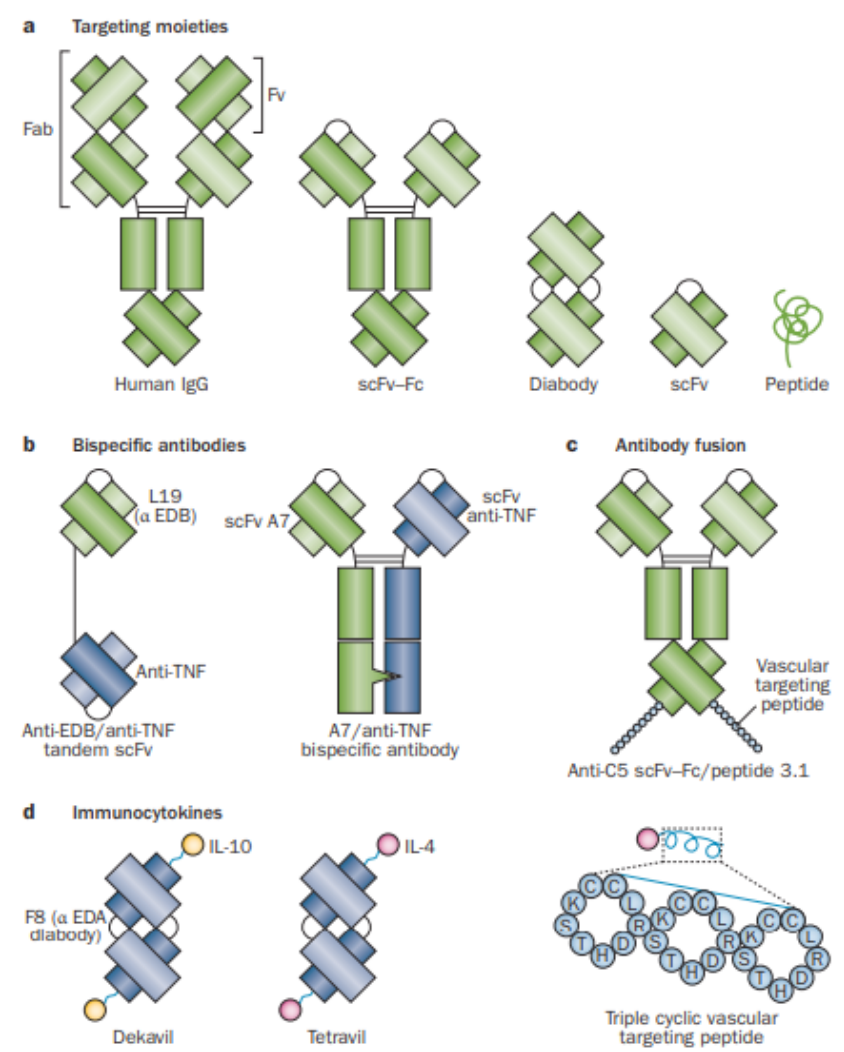

Figure 7. 'Guided Missile' Approaches for Drug Delivery. Formulating (a) drugs as antibodies, antibody derivatives and targeting peptides (b) drugs by the fusion targeting domain of bispecific antibodies to an anti-TNF drug (c) drugs by fusion of two antibodies (d) immunocytokines that target antibody derivatives as drugs, to promote target-specific drug delivery and reduce systemic activation. Abbreviations: $E D A$, extra domain $A$ of fibronectin; $E D B$, extra domain $B$ of fibronectin; scFv, single-chain variable fragment. ${ }^{92}$ 
burden for national healthcare systems.

Finally, though proposed future advances in therapy may improve effectiveness and safety, they however seem incapable of providing complete remission. Thus, advancement in research which aims at achieving a cure should be encouraged.

\section{Authors' Contributions}

$\mathrm{ZB}$, conceived of the concept of the presented review, wrote the manuscript and revised it critically for important intellectual content.

\section{Conflict of Interest Disclosures}

The authors declare they have no conflicts of interest.

\section{References}

1. Jeffery RC. Clinical features of rheumatoid arthritis. Medicine. 2014;42(5):231-236. doi:10.1016/j.mpmed.2014.02.011.

2. Klein K, Ospelt C, Gay S. Epigenetic contributions in the development of rheumatoid arthritis. Arthritis Res Ther. 2012;14(6):227. doi:10.1186/ar4074.

3. Choy EH, Panayi GS. Cytokine pathways and joint inflammation in rheumatoid arthritis. N Engl J Med. 2001;344(12):907-916. doi:10.1056/nejm200103223441207.

4. Viatte S, Plant D, Raychaudhuri S. Genetics and epigenetics of rheumatoid arthritis. Nat Rev Rheumatol. 2013;9(3):141-153. doi:10.1038/nrrheum.2012.237.

5. Carmona L, Cross M, Williams B, Lassere M, March L. Rheumatoid arthritis. Best Pract Res Clin Rheumatol. 2010;24(6):733-745. doi:10.1016/j.berh.2010.10.001.

6. van Vollenhoven RF. Treatment of rheumatoid arthritis: state of the art 2009. Nat Rev Rheumatol. 2009;5(10):531-541. doi:10.1038/ nrrheum.2009.182.

7. Gabriel SE. The epidemiology of rheumatoid arthritis. Rheum Dis Clin North Am. 2001;27(2):269-281. doi:10.1016/S0889857X(05)70201-5.

8. Listing J, Kekow J, Manger B, et al. Mortality in rheumatoid arthritis: the impact of disease activity, treatment with glucocorticoids, TNFalpha inhibitors and rituximab. Ann Rheum Dis. 2015;74(2):415-421. doi:10.1136/annrheumdis-2013-204021.

9. Cross M, Smith E, Hoy D, et al. The global burden of rheumatoid arthritis: estimates from the global burden of disease 2010 study. Ann Rheum Dis. 2014;73(7):1316-1322. doi:10.1136/ annrheumdis-2013-204627.

10. Kitas GD, Gabriel SE. Cardiovascular disease in rheumatoid arthritis: state of the art and future perspectives. Ann Rheum Dis. 2011;70(1):8-14. doi:10.1136/ard.2010.142133.

11. Bingham CO 3rd. The pathogenesis of rheumatoid arthritis: pivotal cytokines involved in bone degradation and inflammation. J Rheumatol Suppl. 2002;65:3-9.

12. Brennan FM, Maini RN, Feldmann M. TNF alpha--a pivotal role in rheumatoid arthritis? Br J Rheumatol. 1992;31(5):293-298. doi:10.1093/rheumatology/31.5.293.

13. Devine EB, Alfonso-Cristancho R, Sullivan SD. Effectiveness of biologic therapies for rheumatoid arthritis: an indirect comparisons approach. Pharmacotherapy. 2011;31(1):39-51. doi:10.1592/ phco.31.1.39.

14. Smolen JS, Aletaha D, Bijlsma JW, et al. Treating rheumatoid arthritis to target: recommendations of an international task force. Ann Rheum Dis. 2010;69(4):631-637. doi:10.1136/ard.2009.123919.

15. Marengo MF, Suarez-Almazor ME. Improving treatment adherence in patients with rheumatoid arthritis: what are the options? Int J Clin Rheumtol. 2015;10(5):345-356. doi:10.2217/ijr.15.39.

16. Feldmann M, Maini RN. Lasker Clinical Medical Research Award. TNF defined as a therapeutic target for rheumatoid arthritis and other autoimmune diseases. Nat Med. 2003;9(10):1245-1250. doi:10.1038/nm939.

17. Wu C, Wang S, Xian P, Yang L, Chen Y, Mo X. Effect of AntiTNF Antibodies on Clinical Response in Rheumatoid Arthritis Patients: A Meta-Analysis. Biomed Res Int. 2016;2016:7185708. doi:10.1155/2016/7185708.

18. Keyser FD. Choice of Biologic Therapy for Patients with Rheumatoid Arthritis: The Infection Perspective. Curr Rheumatol Rev. 2011;7(1):77-87. doi:10.2174/157339711794474620.

19. Hochberg MC, Altman RD, April KT, et al. American College of Rheumatology 2012 recommendations for the use of nonpharmacologic and pharmacologic therapies in osteoarthritis of the hand, hip, and knee. Arthritis Care Res (Hoboken). 2012;64(4):465-474.

20. Alam SM, Kidwai AA, Jafri SR, et al. Epidemiology of rheumatoid arthritis in a tertiary care unit, Karachi, Pakistan. J Pak Med Assoc. 2011;61(2):123-126.

21. Murphy EA, Newsome RC, Galdo JA. Specialty pharmacy: rheumatoid arthritis pharmacotherapy review. J Autoimmun. 2014;39(3):3-6.

22. Lambert DG. Disease-modifying anti-rheumatic drugs. Anaesth Intensive Care Med. 2009;10(1):35-37.

23. Smolen JS, Aletaha D, Koeller M, Weisman MH, Emery $\mathrm{P}$. New therapies for treatment of rheumatoid arthritis. Lancet. 2007;370(9602):1861-1874. doi:10.1016/s0140-6736(07)607843 .

24. O'Dell JR. Therapeutic strategies for rheumatoid arthritis. $N$ Engl J Med. 2004;350(25):2591-2602. doi:10.1056/NEJMra040226.

25. Pincus T, Yazici Y, Sokka T, Aletaha D, Smolen JS. Methotrexate as the "anchor drug" for the treatment of early rheumatoid arthritis. Clin Exp Rheumatol. 2003;21(5 Suppl 31):S179-185.

26. Edwards JC, Szczepanski L, Szechinski J, et al. Efficacy of B-celltargeted therapy with rituximab in patients with rheumatoid arthritis. N Engl J Med. 2004;350(25):2572-2581. doi:10.1056/ NEJMoa032534.

27. Boers M. Does sex of rheumatoid arthritis patients matter? Lancet. 1998;352(9126):419-420. doi:10.1016/s0140-6736(05)79182-0.

28. Scott DL, Wolfe F, Huizinga TW. Rheumatoid arthritis. Lancet. 2010;376(9746):1094-1108. doi:10.1016/s0140-6736(10)608264.

29. Bang LM, Keating GM. Adalimumab: a review of its use in rheumatoid arthritis. BioDrugs. 2004;18(2):121-139. doi:10.2165/00063030-200418020-00005.

30. Gerlag DM, Tak PP. Novel approaches for the treatment of rheumatoid arthritis: lessons from the evaluation of synovial biomarkers in clinical trials. Best Pract Res Clin Rheumatol. 2008;22(2):311-323. doi:10.1016/j.berh.2008.02.002.

31. Klareskog L, van der Heijde D, de Jager JP, et al. Therapeutic effect of the combination of etanercept and methotrexate compared with each treatment alone in patients with rheumatoid arthritis: doubleblind randomised controlled trial. Lancet. 2004;363(9410):675681. doi:10.1016/s0140-6736(04)15640-7.

32. Porter $\mathrm{C}$, Armstrong-Fisher S, Kopotsha T, et al. Certolizumab pegol does not bind the neonatal Fc receptor (FcRn): Consequences for FcRn-mediated in vitro transcytosis and ex vivo human placental transfer. J Reprod Immunol. 2016;116:7-12. doi:10.1016/j. jri.2016.04.284.

33. Kay J, Rahman MU. Golimumab: A novel human anti-TNFalpha monoclonal antibody for the treatment of rheumatoid arthritis, ankylosing spondylitis, and psoriatic arthritis. Core Evid. 2010;4:159-170. doi:10.2147/CE.S6000.

34. Choy EH, Hazleman B, Smith M, et al. Efficacy of a novel PEGylated humanized anti-TNF fragment (CDP870) in patients with rheumatoid arthritis: a phase II double-blinded, randomized, dose-escalating trial. Rheumatology (Oxford). 2002;41(10):11331137. doi:10.1093/rheumatology/41.10.1133.

35. Kaymakcalan Z, Sakorafas P, Bose S, et al. Comparisons of affinities, avidities, and complement activation of adalimumab, infliximab, and etanercept in binding to soluble and membrane 
tumor necrosis factor. Clin Immunol. 2009;131(2):308-316. doi:10.1016/j.clim.2009.01.002.

36. Sakorafas P, Bose S, Kaymakcalan Z. Determination of affinity constants of adalimumab, infliximab and etanercept for soluble and membrane forms of TNF using kinetic exclusion assay (131.22). J Immunol. 2007;178(1):241-242.

37. Arora T, Padaki R, Liu L, et al. Differences in binding and effector functions between classes of TNF antagonists. Cytokine. 2009;45(2):124-131. doi:10.1016/j.cyto.2008.11.008.

38. Mitoma H, Horiuchi $\mathrm{T}$, Tsukamoto $\mathrm{H}$, et al. Mechanisms for cytotoxic effects of anti-tumor necrosis factor agents on transmembrane tumor necrosis factor alpha-expressing cells: comparison among infliximab, etanercept, and adalimumab. Arthritis Rheum. 2008;58(5):1248-1257. doi:10.1002/art.23447.

39. Nesbitt A, Fossati G, Bergin M, et al. Mechanism of action of certolizumab pegol (CDP870): in vitro comparison with other anti-tumor necrosis factor alpha agents. Inflamm Bowel Dis. 2007;13(11):1323-1332. doi:10.1002/ibd.20225.

40. Ringheanu M, Daum F, Markowitz J, et al. Effects of infliximab on apoptosis and reverse signaling of monocytes from healthy individuals and patients with Crohn's disease. Inflamm Bowel Dis. 2004;10(6):801-810. doi:10.1097/00054725-200411000-00015.

41. Agnholt J, Dahlerup JF, Kaltoft K. The effect of etanercept and infliximab on the production of tumor necrosis factor alpha, interferon-gamma and GM-CSF in in vivo activated intestinal T lymphocyte cultures. Cytokine. 2003;23(3):76-85. doi:10.1016/ S1043-4666(03)00201-1

42. Pittoni $V$, Bombardieri M, Spinelli FR, et al. Anti-tumour necrosis factor (TNF) alpha treatment of rheumatoid arthritis (infliximab) selectively down regulates the production of interleukin (IL) 18 but not of IL12 and IL13. Ann Rheum Dis. 2002;61(8):723-725. doi:10.1136/ard.61.8.723.

43. Mitoma $\mathrm{H}$, Horiuchi $\mathrm{T}$, Hatta $\mathrm{N}$, et al. Infliximab induces potent anti-inflammatory responses by outside-to-inside signals through transmembrane TNF-alpha. Gastroenterology. 2005;128(2):376392. doi:10.1053/j.gastro.2004.11.060.

44. Shen C, Assche GV, Colpaert S, et al. Adalimumab induces apoptosis of human monocytes: a comparative study with infliximab and etanercept. Aliment Pharmacol Ther. 2005;21(3):251-258. doi:10.1111/j.1365-2036.2005.02309.x.

45. Ohshima S, Saeki Y, Mima T, et al. Long-term follow-up of the changes in circulating cytokines, soluble cytokine receptors, and white blood cell subset counts in patients with rheumatoid arthritis (RA) after monoclonal anti-TNF alpha antibody therapy. J Clin Immunol. 1999;19(5):305-313. doi:10.1023/a:1020543625282.

46. Huang Z, Yang B, Shi $Y$, et al. Anti-TNF-alpha therapy improves Treg and suppresses Teff in patients with rheumatoid arthritis. Cell Immunol. 2012;279(1):25-29. doi:10.1016/j. cellimm.2012.09.001.

47. Catrina Al, Trollmo C, af Klint E, et al. Evidence that anti-tumor necrosis factor therapy with both etanercept and infliximab induces apoptosis in macrophages, but not lymphocytes, in rheumatoid arthritis joints: extended report. Arthritis Rheum. 2005;52(1):6172. doi:10.1002/art.20764.

48. Van den Brande JM, Braat H, van den Brink GR, et al. Infliximab but not etanercept induces apoptosis in lamina propria T-lymphocytes from patients with Crohn's disease. Gastroenterology. 2003;124(7):1774-1785. doi:10.1016/s0016-5085(03)00382-2.

49. Kim HY, Lee SK, Song YW, et al. A randomized, doubleblind, placebo-controlled, phase III study of the human antitumor necrosis factor antibody adalimumab administered as subcutaneous injections in Korean rheumatoid arthritis patients treated with methotrexate. Int J Rheum Dis. 2007;10(1):9-16. doi:10.1111/j.1479-8077.2007.00248.x.

50. Dinarello CA. Differences between anti-tumor necrosis factoralpha monoclonal antibodies and soluble TNF receptors in host defense impairment. J Rheumatol Suppl. 2005;74:40-47.

51. Shohet JM, Pemberton P, Carroll MC. Identification of a major binding site for complement C3 on the IgG1 heavy chain. J Biol Chem. 1993;268(8):5866-5871.

52. Sahu A, Pangburn MK. Tyrosine is a potential site for covalent attachment of activated complement component C3. Mol Immunol. 1995;32(10):711-716. doi:10.1016/0161-5890(95)98933-f.

53. Sibéril S, Dutertre CA, Boix C, et al. Molecular aspects of human FcgammaR interactions with IgG: functional and therapeutic consequences. Immunol Lett. 2006;106(2):111-118. doi:10.1016/j.imlet.2006.05.009.

54. Horiuchi T, Mitoma H, Harashima S, Tsukamoto H, Shimoda T. Transmembrane TNF-alpha: structure, function and interaction with anti-TNF agents. Rheumatology (Oxford). 2010;49(7):12151228. doi:10.1093/rheumatology/keq031.

55. Watts AD, Hunt NH, Madigan MC, Chaudhri G. Soluble TNF-alpha receptors bind and neutralize over-expressed transmembrane TNFalpha on macrophages, but do not inhibit its processing. J Leukoc Biol. 1999;66(6):1005-1013. doi:10.1002/jlb.66.6.1005.

56. Sarin A, Conan-Cibotti M, Henkart PA. Cytotoxic effect of TNF and lymphotoxin on T lymphoblasts. J Immunol. 1995;155(8):37163718.

57. Neovius M, Arkema EV, Olsson $\mathrm{H}$, et al. Drug survival on TNF inhibitors in patients with rheumatoid arthritis: comparison of adalimumab, etanercept and infliximab. Ann Rheum Dis. 2015;74(2):354-360. doi:10.1136/annrheumdis-2013-204128.

58. Chen YF, Jobanputra $P$, Barton $P$, et al. A systematic review of the effectiveness of adalimumab, etanercept and infliximab for the treatment of rheumatoid arthritis in adults and an economic evaluation of their cost-effectiveness. Health Technol Assess. 2006;10(42):221-229.

59. Hochberg M, Tracy J, Hawkins-Holt M, Flores R. Comparison of the efficacy of the tumor necrosis factor $\alpha$ blocking agents adalimumab, etanercept, and infliximab when added to methotrexate in patients with active rheumatoid arthritis. Ann Rheum Dis. 2003;62(2): ii13-ii16. doi:10.1136/ard.62.suppl_2.ii13.

60. Kavanaugh A, Fleischmann RM, Emery P, et al. Clinical, functional and radiographic consequences of achieving stable low disease activity and remission with adalimumab plus methotrexate or methotrexate alone in early rheumatoid arthritis: 26-week results from the randomized, controlled OPTIMA study. Ann Rheum Dis. 2013;72(1):64-71. doi:10.1136/annrheumdis-2011-201247.

61. Kameda H, UekiY, Saito K, et al. Etanercept (ETN) with methotrexate (MTX) is better than ETN monotherapy in patients with active rheumatoid arthritis despite MTX therapy: a randomized trial. Mod Rheumatol. 2010;20(6):531-538. doi:10.1007/s10165-010-03244.

62. Takeuchi T, Miyasaka N, Inoue K, Abe T, Koike T. Impact of trough serum level on radiographic and clinical response to infliximab plus methotrexate in patients with rheumatoid arthritis: results from the RISING study. Mod Rheumatol. 2009;19(5):478-487. doi:10.1007/s10165-009-0195-8.

63. van der Heijde D, Klareskog L, Rodriguez-Valverde $\mathrm{V}$, et al. Comparison of etanercept and methotrexate, alone and combined, in the treatment of rheumatoid arthritis: two-year clinical and radiographic results from the TEMPO study, a double-blind, randomized trial. Arthritis Rheum. 2006;54(4):1063-1074. doi:10.1002/art.21655.

64. Maini RN, Breedveld FC, Kalden JR, et al. Sustained improvement over two years in physical function, structural damage, and signs and symptoms among patients with rheumatoid arthritis treated with infliximab and methotrexate. Arthritis Rheum. 2004;50(4):1051-1065. doi:10.1002/art.20159.

65. St. Clair EW, Van der Heijde DM, Smolen JS, Maini RN, Bathon JM, Emery P. Combination of infliximab and methotrexate therapy for early rheumatoid arthritis: a randomized, controlled trial. Arthritis Rheum. 2004;50(11):3432-3443. doi:10.1002/art.20568.

66. Wiens A, Venson R, Correr CJ, Otuki MF, Pontarolo R. Meta-analysis of the efficacy and safety of adalimumab, etanercept, and infliximab for the treatment of rheumatoid arthritis. Pharmacotherapy. 
2010;30(4):339-353. doi:10.1592/phco.30.4.339.

67. Hetland ML, Christensen IJ, Tarp U, et al. Direct comparison of treatment responses, remission rates, and drug adherence in patients with rheumatoid arthritis treated with adalimumab, etanercept, or infliximab: results from eight years of surveillance of clinical practice in the nationwide Danish DANBIO registry. Arthritis Rheum. 2010;62(1):22-32. doi:10.1002/art.27227.

68. Frazier-Mironer A, Dougados M, Mariette X, et al. Retention rates of adalimumab, etanercept and infliximab as first and second-line biotherapy in patients with rheumatoid arthritis in daily practice. Joint Bone Spine. 2015; 81(4):353-359. doi:10.1002/art.27227.

69. Dogra S, Khullar G. Tumor necrosis factor- $\alpha$ antagonists: side effects and their management. Indian J Dermatol Venereol Leprol. 2013;79 Suppl 7:S35-S46. doi:10.4103/0378-6323.115526.

70. Choy EH, Kavanaugh AF, Jones SA. The problem of choice: current biologic agents and future prospects in RA. Nat Rev Rheumatol. 2013;9(3):154-163. doi:10.1038/nrrheum.2013.8.

71. Hassan S, Milman U, Feld J, et al. Effects of anti-TNF-alpha treatment on lipid profile in rheumatic diseases: an analytical cohort study. Arthritis Res Ther. 2016;18(1):261. doi:10.1186/ s13075-016-1148-1.

72. Ramanarayanan J, Pahuja S, Czuczman MS, Hernandez-Ilizaliturri FJ. Tumor Necrosis Factor Alpha (TNF-a) Blockade and Risk of Lymphoma: Systematic Review and Analysis of Literature. Blood. 2008;112(11):5278.

73. Humira ${ }^{\circledR}$ Injection Prescribing Information and Medication Guide https://www.fda.gov/downloads/drugs/drugsafety/ucm088611. pdf. Accessed April 3, 2018. Published 2009.

74. Wallis RS, Broder MS, Wong JY, Hanson ME, Beenhouwer DO. Granulomatous infectious diseases associated with tumor necrosis factor antagonists. Clin Infect Dis. 2004;38(9):1261-1265. doi:10.1086/383317.

75. Schneeweiss S, Setoguchi S, Weinblatt ME, et al. Anti-tumor necrosis factor alpha therapy and the risk of serious bacterial infections in elderly patients with rheumatoid arthritis. Arthritis Rheum. 2007;56(6):1754-1764. doi:10.1002/art.22600.

76. Wolbink GJ, Vis M, Lems W, et al. Development of antiinfliximab antibodies and relationship to clinical response in patients with rheumatoid arthritis. Arthritis Rheum. 2006;54(3):711-715. doi:10.1002/art.21671.

77. Strand V, Kimberly R, Isaacs JD. Biologic therapies in rheumatology: lessons learned, future directions. Nat Rev Drug Discov. 2007;6(1):75-92. doi:10.1038/nrd2196.

78. Baert F, Noman M, Vermeire $S$, et al. Influence of immunogenicity on the long-term efficacy of infliximab in Crohn's disease. N Engl J Med. 2003;348(7):601-608. doi:10.1056/NEJMoa020888.

79. Mocci G, Marzo M, Papa A, Armuzzi A, Guidi L. Dermatological adverse reactions during anti-TNF treatments: focus on inflammatory bowel disease. J Crohns Colitis. 2013;7(10):769779. doi:10.1016/j.crohns.2013.01.009.

80. Lipsky PE, Van der Heijde DM, St. Clair WE, et al. Infliximab and methotrexate in the treatment of rheumatoid arthritis. N Eng J Med. 2000;343(1):1594-1602. doi:10.1056/NEJM200011303432202.

81. Westhovens R, Yocum D, Han J, et al. The safety of infliximab, combined with background treatments, among patients with rheumatoid arthritis and various comorbidities: a large, randomized, placebo-controlled trial. Arthritis Rheum. 2006;54(4):1075-1086. doi:10.1002/art.21734.

82. Weinblatt ME, Kremer JM, Bankhurst $A D$, et al. A trial of etanercept, a recombinant tumor necrosis factor receptor: $F_{C}$ fusion protein, in patients with rheumatoid arthritis receiving methotrexate. N Eng J Med. 1999;340(4):253-259. doi:10.1056/ NEJM199901283400401.

83. Bathon JM, Martin RW, Fleischmann RM, et al. A comparison of etanercept and methotrexate in patients with early rheumatoid arthritis. N Eng J Med. 2000;343(22):1586-1593. doi:10.1056/ NEJM200011303432201.

84. Weinblatt ME, Keystone EC, Furst DE, et al. Adalimumab, a fully human anti-tumor necrosis factor alpha monoclonal antibody, for the treatment of rheumatoid arthritis in patients taking concomitant methotrexate: the ARMADA trial. Arthritis Rheum. 2003;48(1):3545. doi:10.1002/art.10697.

85. Van de Putte LB, Atkins C, Malaise M, Sany J, et al. Efficacy and safety of adalimumab as monotherapy in patients with rheumatoid arthritis for whom previous disease modifying antirheumatic drug treatment has failed. Ann Rheum Dis. 2004;63(5):508-516. doi:10.1136/ard.2003.013052.

86. Keystone EC, Kavanaugh AF, Sharp JT, et al. Radiographic, clinical, and functional outcomes of treatment with adalimumab (a human anti-tumor necrosis factor monoclonal antibody) in patients with active rheumatoid arthritis receiving concomitant methotrexate therapy: a randomized, placebo-controlled, 52-week trial. Arthritis Rheum. 2004;50(5):1400-1411. doi:10.1002/art.20217.

87. Breedveld FC, Weisman MH, Kavanaugh AF, et al. The PREMIER study: a multicenter, randomized, double-blind clinical trial of combination therapy with adalimumab plus methotrexate versus methotrexate alone or adalimumab alone in patients with early, aggressive rheumatoid arthritis who had not had previous methotrexate treatment. Arthritis Rheum. 2006;54(1):26-37. doi:10.1002/art.21519.

88. van Dartel SAA, Fransen J, Kievit W, et al. Difference in the risk of serious infections in patients with rheumatoid arthritis treated with adalimumab, infliximab and etanercept: results from the Dutch Rheumatoid Arthritis Monitoring (DREAM) registry. Ann Rheum Dis. 2013;72(6):895-900. doi:10.1136/annrheumdis-2012-201338.

89. Alonso-Ruiz A, Pijoan JI, Ansuategui E, Urkaregi A, Calabozo M, Quintana A. Tumor necrosis factor alpha drugs in rheumatoid arthritis: systematic review and meta-analysis of efficacy and safety. BMC Musculoskelet Disord. 2008;9:52. doi:10.1186/1471_ 2474-9-52.

90. Quinn MA, Conaghan PG, O'Connor PJ, et al. Very early treatment with infliximab in addition to methotrexate in early, poor-prognosis rheumatoid arthritis reduces magnetic resonance imaging evidence of synovitis and damage, with sustained benefit after infliximab withdrawal: results from a twelve-month randomized, doubleblind, placebo-controlled trial. Arthritis Rheum. 2005;2(1):27-35. doi:10.1002/art.20712.

91. Lee, SM, Kim HJ, Ha YJ, Park YN, Lee SK, Park YB and Yoo KH. Targeted chemo-photothermal treatments of rheumatoid arthritis using gold half-shell multifunctional nanoparticles. ACS Nano. 2013;7(1):50-57. doi:10.1021/nn301215q.

92. Ferrari M, Onuoha SC, Pitzalis C. Trojan horses and guided missiles: targeted therapies in the war on arthritis. Nat Rev Rheumatol. 2015;11(6):328-337. doi:10.1038/nrrheum.2015.17.

93. Burska AN, Roget $K$, Blits $M$, et al. Gene expression analysis in RA: towards personalized medicine. Pharmacogenomics J. 2014;14(2):93-106. doi:10.1038/tpj.2013.48. 